\title{
Maternal/Child Social Support and Food Security in Relation to Child Height and BMI in Four Lmics: Mediation Analysis of Young Lives Data
}

Hwa-Young Lee

Harvard T.H.Chan School of Public Health

In Han Song ( $\boldsymbol{D}$ isong@yonsei.ac.kr)

Yonsei University

Ichiro Kawachi

Harvard T.H. Chan School of Public Health

\section{Research Article}

Keywords: social support, child height, child BMI, mediation analysis, low-and middle-income country.

Posted Date: July 12th, 2021

DOI: https://doi.org/10.21203/rs.3.rs-673304/v1

License: (c) (i) This work is licensed under a Creative Commons Attribution 4.0 International License.

Read Full License 


\title{
Maternal/child social support and food security in relation to child height and BMI in four LMICs: Mediation analysis of Young Lives data
}

\author{
Hwa-Young Lee ${ }^{1,2}$, In Han Song $2,3 *$, Ichiro Kawachi ${ }^{4}$.
}

1. Department of Global Health and Population, Harvard T.H.Chan School of Public Health, 677 Huntington Ave, Boston MA 20115, USA

(Email: hwlee@hsph.harvard.edu)

2. Institute of Convergence Science (ICONS), Convergence Science Academy, Yonsei University, 50 Yonsei-ro Seodaemun-gu, Seoul, 03722, The Republic of Korea

3. Graduate School of Social Welfare, Yonsei University, Seoul, 03722, The Republic of Korea

(Email: isong@yonsei.ac.kr)

4. Department of Social and Behavioral Sciences, Harvard T.H. Chan School of Public Health, 677 Huntington Ave, Boston MA 20115, USA

(Email: ikawachi@hsph.harvard.edu)

Short title: social support, food security, and child anthropometry

Number of tables: 2 / number of figures: 3/supplementary materials :1

Words count: 3,423

Corresponding Author:

In Han Song

Graduate School of Social Welfare, Yonsei University 50 Yonsei-ro Seodaemun-gu, Seoul, 03722, The Republic of Korea

E-mail: isong@yonsei.ac.kr 


\begin{abstract}
Background

Poor nutritional status in childhood is associated with an elevated risk of mortality and morbidity later in life. Previous studies showed a positive association between specific types of social capital and child nutritional status. Our study examined whether improved food security mediates the impact of maternal and child social support on child height and body mass index (BMI) in four low- and middle-income countries.
\end{abstract}

\title{
Methods
}

We used data from the Young Lives cohort study comprising roughly 1,000 children at age 8 and 12 in Vietnam, Ethiopia, India, and Peru. Outcome variables were z-score for height (HAZ) and BMI (BAZ).

\section{Results}

Belonging to the top half of maternal financial support and child financial support was positively associated with child HAZ at age 12 in Peru. Belonging to top half of overall maternal support among children aged 8 in Vietnam, and maternal financial support among children aged 12 in India were also positively associated with child BAZ. A positive association of food security was only found with maternal financial support among children aged 12 in Peru. However, food security did not play a significant role in mediating the effect of maternal financial support on child HAZ at age 12. 


\section{Conclusions}

Strengthening social support to improve child nutritional status may not be a sufficient intervention in resource-poor settings because sources of supports may lack sufficient food

resources to share. Considering between-country heterogeneity, a "one size fits all" approach for enhancing social capital may not be appropriate.

Key words; social support, child height, child BMI, mediation analysis, low-and middle-income country. 


\section{Introduction}

Poor nutritional status in childhood has been linked to elevated risk of mortality and morbidity later in life. ${ }^{1}$ Not only does impaired physical growth hamper child development (defined as the attainment of gross motor and fine motor skills), psychosocial competencies, and cognitive abilities, ${ }^{23}$ it also raises a risk of infectious disease. ${ }^{4}$ However, the worldwide prevalence of child anthropometric failure including stunting, underweight, and wasting remain stubbornly high and are concentrated in Low and Middle-Income Countries (LMICs). In 2019, 38\% and 34.5\% of children aged 0-59 months in Eastern Africa and Oceania were estimated to have stunting respectively, which is more than 15 times higher than in Northern America (2.6\%). ${ }^{5}$

According to the United Nations Children's Fund (UNICEF) framework of determinants of child undernutrition, household food security is one of the important factors for child undernutrition which is in turn affected by socioeconomic conditions and the national/global context. ${ }^{6}$ Food insecurity leads to inadequate dietary intake which affects height and weight directly as well as indirectly by promoting disease occurrence. This was empirically demonstrated in Humphries (2015) where children from chronically food-insecure households in Ethiopia, India, Peru, and Vietnam had significantly lower Height for Age Z-score (HAZ) compared to households that were consistently food-secure. ${ }^{7}$

Social capital, defined as the resources embedded within social networks, ${ }^{8}$ has been demonstrated to positively affect health. Social capital can be analyzed as an individual attribute, i.e., as an individual's access to social support within a network. Social capital can be analyzed also as a property of the collective, e.g., norms of mutual assistance within a group. ${ }^{910}$ Although 
social capital has long been discussed in social sciences, the emergence of social capital in development practice is relatively recent. ${ }^{11}$ Several studies have found a positive association between maternal or household social capital and child nutritional status. ${ }^{12-15}$ However, it is difficult to reach any definite conclusion because characteristics of the sample and measure of social capital varied from study to study, and the results have been mixed. ${ }^{12-15}$

Studies that found a positive association between social capital and child nutritional status suggested that increased food security may be the mechanism, whereby individuals share food resources within their network or gain access to knowledge of where to obtain cheap sources of food. A handful of studies have demonstrated an association between social capital and household hunger or food security. ${ }^{16-18}$ However, most of these took place in high-income countries (HICs) where food security is good on average, and therefore, there is an abundant source of supports that food-insecure households can borrow food or receive food assistance from. Only one study based in the LMIC setting has examined the role of social capital in the context of a food support program within their community. ${ }^{19}$ Furthermore, none of studies examined the mediating role of food security in the effect of social capital on child nutritional status in any settings.

The results from these prior studies about association among maternal social capital, food security, and child nutritional status calls for the need to assess the role of food security in the association between social capital and child nutritional status in LMICs. Although school-age children are old enough to develop their own social networks or to participate in groups while they are still in a growing phase, no studies have evaluated the association between child's social 
support and their nutritional status. Thus, our study aimed to examine 1) whether maternal and child social support is associated with child height and Body Mass Index (BMI) 2) whether these associations are mediated by food security.

\section{Methods}

\section{Study design}

Data were obtained from the older cohort of the Young Lives (YL) study, an international and longitudinal cohort survey performed in Ethiopia, India, Peru, and Vietnam. ${ }^{20}$ The older cohort of the YL study comprises around 1,000 children aged 8 years when recruited in 2002 (wave 1). Subsequent data were collected at age 12 years in 2006 (wave 2), 15 years in 2009 (wave 3), 19 years in 2013 (wave 4), and finally at age 22 years in 2016 (wave 5). Data for our analysis were extracted from waves 1 and 2.

The YL study employed a clustered multistage sampling strategy in each country. At the first stage, 20 sentinel sites were selected in each country by semi-purposive sampling with slight oversampling of poor sites to serve the main study objective to explore the causes and consequences of childhood poverty. ${ }^{20}$ For example, the most food-insecure areas encompassed the sampling universe in Ethiopia. In Peru, the richest 5\% of districts were excluded from the sample. However, final samples represent a range of regions, policy contexts, and living conditions. ${ }^{7}$ The cohort in India consisted only of households from Andhra Pradesh while cohorts in the other three countries were nationwide. At the second stage, all households with children of the right age within the sites were listed, from which 100 households were randomly selected at each site. ${ }^{21}$ 
The response rate was above $90 \%$ in all the countries. Data were collected by a standardized, interviewer-administered questionnaire from the child's main caregiver.

\section{Study indicators}

\section{Child anthropometry}

We assessed both child height and BMI, which is affected by chronic and acute nutritional status respectively. ${ }^{22}$ Height was measured using stadiometers with standing plates and moveable headboard which were locally made, and weight was measured by calibrated digital balance (Soehnle). Height-for-Age Z score (HAZ) and BMI for -Age Z score (BAZ) were calculated using the WHO 2007 standard. ${ }^{23}$ Staffs were adequately trained to measure anthropometries and utilized techniques according to WHO guidelines. ${ }^{24} 25$ Extreme z-scores deemed biologically implausible (<-6 and $>6$ for HAZ, and $<-5$ and $>5$ for BAZ) were dropped according to the WHO recommendation. ${ }^{26}$

Food security

Food security was asked differently in wave 1 and 2. In wave 1, respondents were asked whether the household had gotten enough food to eat while in wave 2, they were asked whether the household had experienced any food shortage in the last 12 months. "Yes" in wave 1 and "no" in wave 2 was coded as one indicating that the household was food-secure.

Social support

Different questions were used to capture social support across waves. In wave 1, only maternal social support was measured while both maternal and child social support was 
measured in wave 2. The Short Social Capital Assessment Tool (SASCAT) was used to measure maternal social capital in wave 1, which is a shortened version of Adapted Social Capital Tool (ASCAT). SASCAT included three aspects of structural social capital; membership of groups, involvement in citizenship activities, and social support). SASCAT was validated in Vietnam and Peru. ${ }^{27} 28$ We only utilized the social support items for our study. Support received from groups in which the mother participated (support from groups) as well as social support received from different types of individuals (support from individuals) were combined into an index of maternal social support. For support from groups, when the respondent answered that they belonged to any of seven different kinds of groups (trade union, community association/co-op, women's group, political group, religious group, credit/funeral group, and sports group), they were subsequently asked whether they had received any support from that group. For support from individual, participants were asked whether they had received support from any of nine different types of individuals (e.g., family, neighbors, friends and so on). As has been the case in previous papers, ${ }^{1429}$ a total score of maternal social support was calculated by summing the number of 'yes' resulting in a score range from 0 to 16 . Then, we categorized the total score by the median split. In wave 2, only financial support was examined for mothers while child social support was examined comprehensively. Specifically, mothers were asked how many people they could rely for material or financial support with seven response options (none, 1, 2, 3 5, 6 10, 11 15, 16 20, 12 30, and >30). Responses were then dichotomized into Yes (none) versus No (all others). Children were asked whether there is someone who can help in six different types of situations (detailed questions were described in Table S1). The overall level of child support was calculated 
by summing positive responses resulting in a range of $0 \sim 6$, which were categorized by median split. Some countries showed a skewed distribution of maternal and child social supports (presented in blue and red arrows in Fig 2.1 and Fig 2.3). We additionally examined financial support for the child based on the question asking whether the child has someone who can help when they needed pocket money (Table S1).

\section{Covariates}

Child characteristics included gender (female vs. male), birth order $\left(2^{\text {nd }}, 3^{\text {rd }}\right.$, and higher than $4^{\text {th }}$ vs. $1^{\text {st }}$ ), and child's working status (yes vs. no). Caregiver factors included age in five-year bands $(30 \geqq \&<35,35 \geqq \&<40$, and $40 \geqq$ vs. $<30)$, education level (completed vs. not completed primary), and marital status (permanent partner vs. divorced, separated, single or widowed). Household characteristics included household size (5 or 6 , and $>6$ vs. $\leqq 4$ ), residential location (rural vs. urban), and wealth quintiles $\left(2^{\text {nd }}, 3^{\text {rd }}, 4^{\text {th }}\right.$ and $5^{\text {th }}$ vs. $\left.1^{\text {st }}\right)$. Wealth quintile was based on a wealth index ranging from 0 to 1 which was calculated by averaging three variables: housing quality, ownership of consumer durables, and access to services.

\section{Statistical analyses}

First, we summarized the distributions of maternal and child's social support, as well as HAZ and BAZ according to maternal, child, and household characteristics for each of four countries. Then, associations between level of maternal or child's social support and child's HAZ and BAZ at age 8 and 12 were assessed using multivariable linear regression models. We 
introduced the community cluster effect $\left(\varepsilon_{1}, \varepsilon_{2}\right.$, and $\left.\varepsilon_{3}\right)$ to the model using the 'cluster' option in the STATA package. The model can be specified as follows;

$$
\begin{gathered}
H A Z \text { or } B A Z=\alpha_{1}+\gamma \text { maternal or child social support }+\emptyset_{1} X_{1}+\varepsilon_{1} \text {, } \\
\text { where } \varepsilon_{1} \sim \mathrm{N}\left(0, \sigma_{\varepsilon}^{2}\right)
\end{gathered}
$$

Where $\mathrm{X} 1$ includes control variables except for food security, and $\varepsilon_{1}$ is a community random effect.

Next, to explore the mediating effect of food security in the association between social support and child height and BMI, we fit a meditation model. We examined whether maternal or child social support which showed a significant association with HAZ or BAZ in equation (1) is associated with the probability of having food security, using the following reduced-form specification.

$$
\left(\text { logit } \frac{p(\text { being food-secure })}{1-p(\text { being food-secure })}\right)=\alpha_{2}+\beta \text { maternal or child social support }+\emptyset_{2} X_{2}+\varepsilon_{2}
$$

Where $\mathrm{X}_{2}$ includes control variables that have proved to be strongly associated with food security (household size, mother's education, and wealth level). For mediation to be present, $\beta$ in equation (2) needs to be significantly different from 0 . Finally, we introduced the food security variable in the equation (1).

HAZ or BAZ $=\alpha_{3}+\gamma^{\prime}$ maternal or child social support $+\sum_{i} \delta_{i}$ Food security $+\emptyset_{3} X_{3}+\varepsilon_{3}-$ --- (3) 
Where $\delta$ in (3) needs to be significantly different from 0 and $\gamma^{\prime}$ in (3) is either 0 or less than $\gamma$ in (1) in absolute value for mediation to be present. The relations described above can be visualized as a mediation model proposed by Baron and Kenny (Fig 1) ${ }^{30}$.

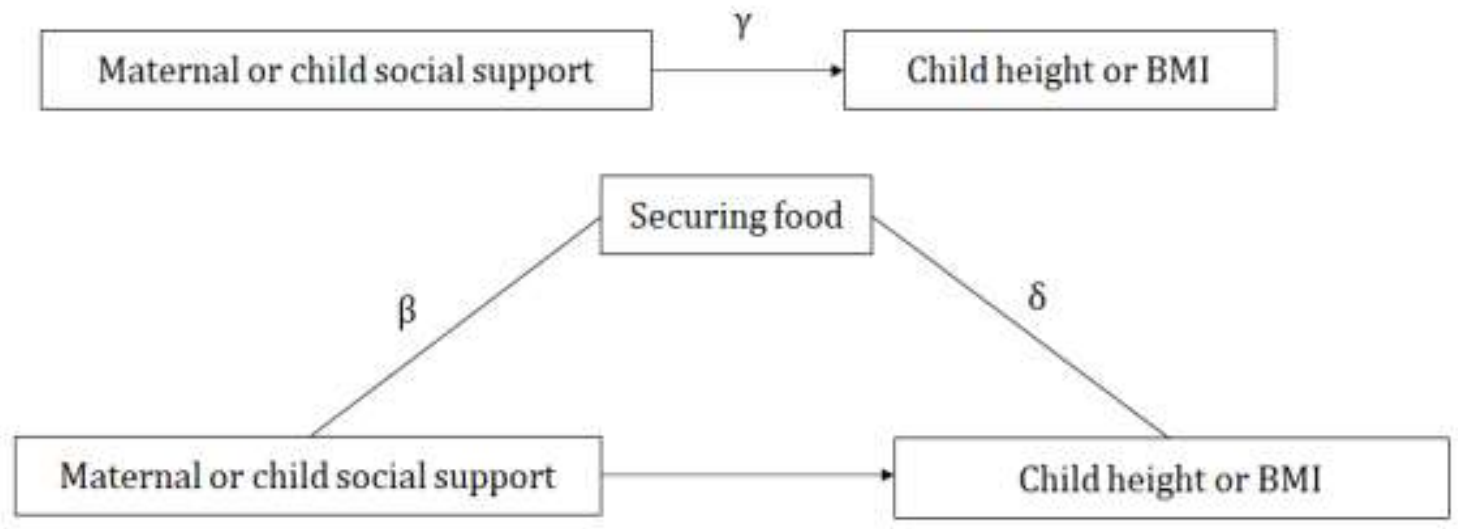

Figure 1. The mediation model.

However, this process does not fit well for non-linear mediators. Further, it is difficult to make a causal interpretation due to a potential omitted variable bias. To address these issues, we used the potential outcome framework introduced by Imai et al (2010) that use counterfactuals to identify causal effect and decomposes the total effect of a variable into direct and indirect (i.e., meditational) effect. ${ }^{31}{ }^{32}$ In Imai et al 's model, the total effect is $\beta$ in the equation 1 , which is a total effect of social support on HAZ or BAZ (without food security effect). Average direct effect (ADE) is the mean difference between two counterfactual states of initial conditions, assuming no change in the mediator ( $\gamma^{\prime}$ in equation (3)), which is a direct effect of social support on HAZ or BAZ after taking into account a mediation (indirect) effect of food security. Finally, average causal mediation effects (ACME) are defined as the mean difference in effect between two counterfactual 
states of a mediator, assuming no change in the initial condition (total effect subtracted by direct effect : $\gamma-\gamma^{\prime}$, which equals to a product of the coefficient of $\beta$ in the equation (1) and $\delta$ in equation (3)). Mediation analysis was performed using use written code -medeff- in STATA $14 . .^{33-35}$ Analyses were performed separately by wave (age 8 and age 12) and country.

\section{Results}

The pattern of social supports greatly differed between settings (Fig 2). The average number of maternal social supports was highest in Vietnam (3.26), followed by Ethiopia (2.40). The average number of child supports was highest in India where $91.5 \%$ of children respondents answered that they had someone to help in all six different kinds of situations. The relationship between the level of maternal and child social support and average HAZ and BAZ was not consistent across the countries. 


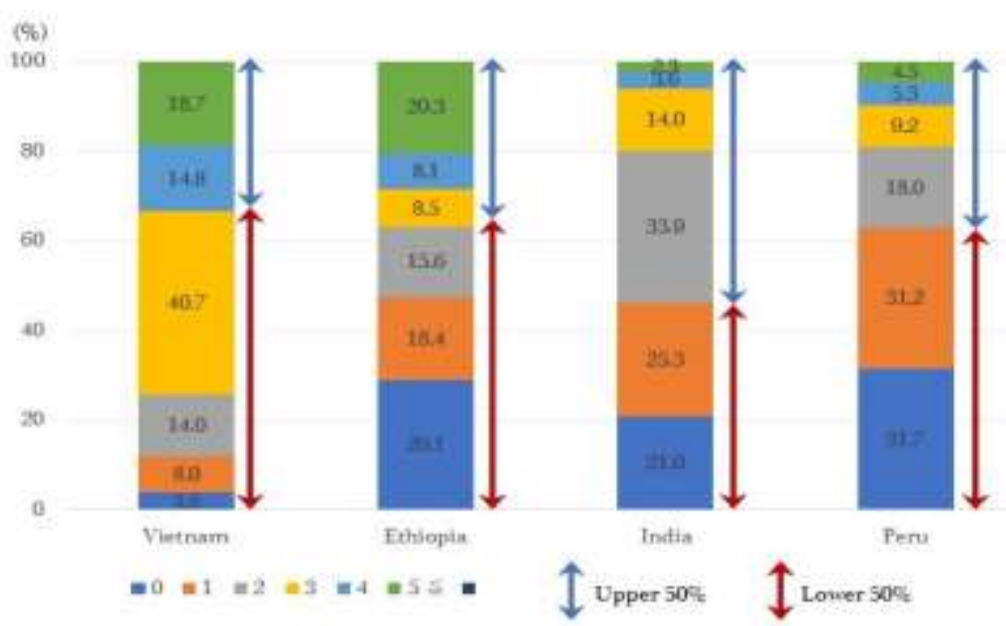

Fig 2.1 Distribution of maternal social support at wave 1

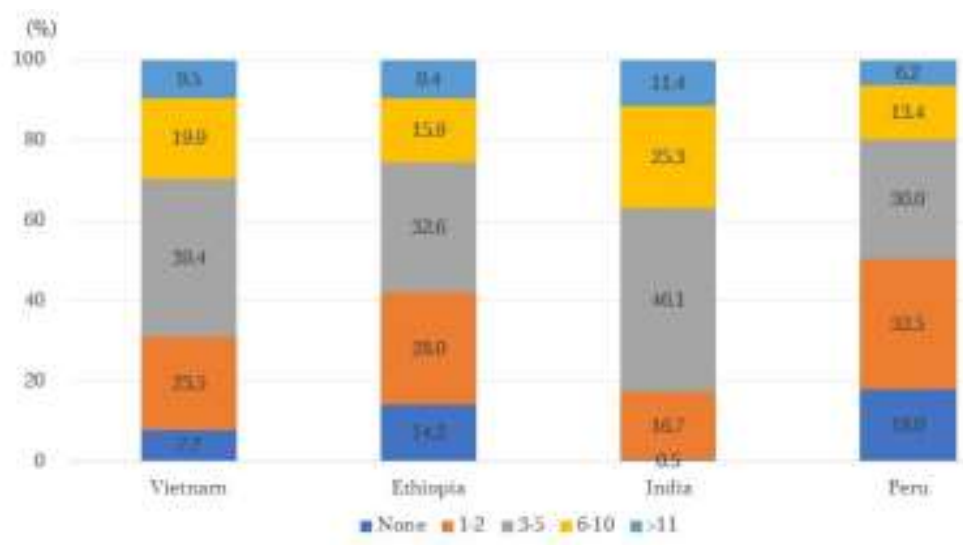

Fig 2.2 Distribution of maternal financial support at wave 2

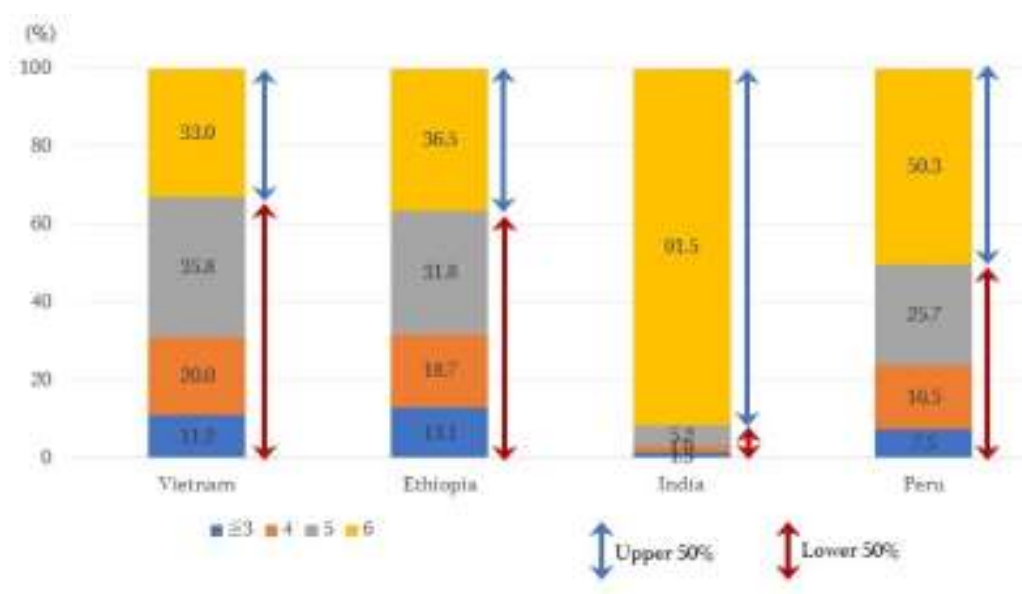

Fig 2.3 Distribution of child social support at wave 2

\begin{tabular}{|c|c|c|c|}
\hline \multicolumn{2}{|c|}{} & L50\% & U50\% \\
\hline \multirow{4}{*}{ Vietnam } & Avg.SS & 2.38 & 4.96 \\
& zhfa & -1.47 & -1.45 \\
& zbfa & -1.15 & -1.09 \\
\hline \multirow{4}{*}{ Ethiopia } & Avg.SS & 0.73 & 5.26 \\
& zhfa & -1.46 & -1.56 \\
& zbfa & -1.25 & -1.32 \\
\hline \multirow{4}{*}{ Peru } & Avg.SS & 0.55 & 2.55 \\
& zhfa & -1.5 & -1.54 \\
& zbfa & -1.41 & -1.37 \\
\hline & Avg.SS & 0.50 & 2.96 \\
& zhfa & -1.35 & -1.46 \\
& zbfa & 0.45 & 0.56 \\
\hline
\end{tabular}

Avg.SS: Average number of maternal social supports

\begin{tabular}{|c|c|c|c|}
\hline \multicolumn{2}{|c|}{} & No & Yes \\
\hline \multirow{2}{*}{ Vietnam } & zhfa & -1.56 & -1.44 \\
& zbfa & -1 & -1.01 \\
\hline \multirow{2}{*}{ Ethiopia } & zhfa & -1.22 & -1.41 \\
& zbfa & -1.58 & -1.7 \\
\hline \multirow{2}{*}{ India } & zhfa & -1.31 & -1.53 \\
& zbfa & -2.55 & -1.46 \\
\hline \multirow{2}{*}{ Peru } & zhfa & -1.64 & -1.44 \\
& zbfa & 0.26 & 0.26 \\
\hline
\end{tabular}

\begin{tabular}{|c|c|c|c|}
\hline \multicolumn{2}{|c|}{} & L50\% & U50\% \\
\hline \multirow{4}{*}{ Vietnam } & Ave.SS & 4.3 & 6 \\
& zhfa & -1.48 & -1.34 \\
& zbfa & -1.01 & -1.04 \\
\hline \multirow{4}{*}{ Ethiopia } & Ave.SS & 4.1 & 6 \\
& zhfa & -1.34 & -1.44 \\
& zbfa & -1.67 & -1.71 \\
\hline \multirow{3}{*}{ India } & Ave.SS & 4.3 & 6 \\
& zhfa & -1.36 & -1.56 \\
& zbfa & -1.38 & -1.49 \\
\hline \multirow{4}{*}{ Peru } & Ave.SS & 4.3 & 6 \\
& zhfa & -1.53 & -1.42 \\
& zbfa & 0.26 & 0.26 \\
\hline
\end{tabular}

Avg.SS: Average number of child social supports

Figure 2. Distribution of social support 
Table S2 shows the descriptive statistics of the study samples at wave 1 from Vietnam, Ethiopia, India, and Peru and the mean HAZ and BAZ for each category (characteristics of study samples at wave 2 hardly changed from wave 1 because the Young Lives data is a cohort survey). Generally, children with higher HAZ/BAZ were more likely to be from households that had fewer household members, were wealthier and more likely to be in an urban area. The average BAZ for the entire sample was remarkably high in Peru compared to other countries in both waves.

Table 1. Association between maternal and child support and child z-score for height at wave 1 and 2 in four countries from linear regression adjusted for community cluster effect.

\begin{tabular}{|c|c|c|c|c|c|c|c|c|c|c|}
\hline & \multicolumn{2}{|c|}{ Vietnam } & \multicolumn{2}{|c|}{ Ethiopia } & \multicolumn{2}{|c|}{ India } & \multicolumn{2}{|c|}{ Peru } \\
\hline & & & $\mathrm{b}$ & SE & $\mathrm{b}$ & SE & $\mathrm{b}$ & SE & $\mathrm{b}$ & SE \\
\hline \multicolumn{11}{|l|}{ HAZ } \\
\hline \multirow{3}{*}{ Wave 1} & \multirow{3}{*}{$\begin{array}{l}\text { Overall maternal } \\
\text { social support }\end{array}$} & Continuous & -0.025 & 0.016 & -0.005 & 0.032 & 0.001 & 0.031 & -0.019 & 0.029 \\
\hline & & Binary $(\operatorname{Ref}=$ & - & - & - & - & - & - & - & - \\
\hline & & Upp & $-0.131^{*}$ & 0.052 & 0.001 & 0.131 & 0.008 & 0.92 & -0.116 & 0.090 \\
\hline \multirow{8}{*}{$\begin{array}{c}\text { Wave } \\
2\end{array}$} & \multirow{3}{*}{$\begin{array}{l}\text { Maternal } \\
\text { financial } \\
\text { support }\end{array}$} & Contir & -0.002 & 0.014 & 0.028 & 0.039 & 0.009 & 0.053 & 0.027 & 0.017 \\
\hline & & Binar & - & - & - & - & - & - & - & - \\
\hline & & Yes & -0.023 & 0.034 & -0.049 & 0.102 & 0.066 & 0.306 & $0.111^{*}$ & 0.031 \\
\hline & \multirow{3}{*}{$\begin{array}{l}\text { Overall child } \\
\text { support }\end{array}$} & Continuous & -0.007 & 0.020 & -0.027 & 0.023 & -0.041 & 0.037 & 0.030 & 0.020 \\
\hline & & Binary $(\operatorname{Ref}=1$ & - & - & - & - & - & - & - & - \\
\hline & & Uppe & -0.055 & 0.029 & -0.069 & 0.063 & -0.114 & 0.095 & 0.020 & 0.048 \\
\hline & Child financial & Binary $(\operatorname{Ref}=$ & - & - & - & - & - & - & - & - \\
\hline & support & Yes & 0.072 & 0.826 & $-0.160^{*}$ & 0.070 & 0.120 & 0.140 & $0.151^{*}$ & 0.065 \\
\hline \multicolumn{11}{|l|}{ BAZ } \\
\hline \multirow[b]{2}{*}{$\begin{array}{l}\text { Wave } \\
1\end{array}$} & \multirow[b]{2}{*}{$\begin{array}{l}\text { Overall maternal } \\
\text { social support }\end{array}$} & Continuous & 0.014 & 0.020 & -0.015 & 0.029 & 0.029 & 0.027 & 0.028 & 0.023 \\
\hline & & $\begin{array}{l}\text { Binary (Ref= lower } 50 \%) \\
\text { Upper } 50 \%\end{array}$ & 0.024 & 0.066 & -0.120 & 0.142 & 0.069 & 0.067 & 0.087 & 0.080 \\
\hline \multirow{6}{*}{$\begin{array}{c}\text { Wave } \\
2\end{array}$} & \multirow[b]{2}{*}{$\begin{array}{l}\text { Maternal } \\
\text { financial support }\end{array}$} & Continuous & 0.026 & 0.029 & -0.014 & 0.038 & $0.077^{*}$ & 0.036 & 0.032 & 0.029 \\
\hline & & $\begin{array}{l}\text { Binary }(\text { Ref= no }) \\
\text { Yes }\end{array}$ & 0.112 & 0.150 & -0.110 & 0.133 & $1.216^{* *}$ & 0.222 & 0.003 & 0.114 \\
\hline & \multirow{3}{*}{$\begin{array}{l}\text { Overall child } \\
\text { support }\end{array}$} & Continuous & -0.024 & 0.040 & -0.023 & 0.033 & -0.057 & 0.065 & -0.016 & 0.030 \\
\hline & & Binary $(\operatorname{Ref}=1$ & & & & & & & & \\
\hline & & Upper $50 \%$ & -0.077 & 0.106 & -0.005 & 0.073 & -0.095 & 0.134 & -0.024 & 0.069 \\
\hline & $\begin{array}{l}\text { Child financial } \\
\text { support }\end{array}$ & $\begin{array}{l}\text { Binary }(\text { Ref= No }) \\
\text { Yes }\end{array}$ & -0.056 & 0.114 & -0.079 & 0.086 & 0.130 & 0.191 & 0.093 & 0.093 \\
\hline
\end{tabular}

b: coefficient from linear regression, SE: Standard error $\left({ }^{*}: \mathrm{p}<0.05,{ }^{* *}: \mathrm{p}<0.01\right)$ 
The results of the association between maternal and child social support and HAZ at wave 1 and 2 were mixed (Table 1). At wave 1 when the child was 8 years old, children of mothers in Vietnam whose overall level of social support belonged to the upper $50 \%$ were likely to be lower in HAZ, which was against our expectation. There was no significant association in the other three countries. At wave 2, only Peru showed a positive association between the level of maternal financial support and child's HAZ. Child financial support was negatively associated with HAZ in Ethiopia while it was positively associated in Peru. The overall level of child support showed no association in any countries. As for BAZ, only the level of maternal financial support, operationalized both as a continuous and binary variable, showed a positive association when a child is 12 years old in India (Table 1).

Table 2. Association between maternal and child social support and food security at waves 1 and 2 in four countries from logistic regression adjusted for community cluster effect.

\begin{tabular}{|c|c|c|c|c|c|}
\hline & & Vietnam & Ethiopia & India & Peru \\
\hline & & OR $(95 \% \mathrm{CI})$ & OR $(95 \%$ CI) & OR $(95 \% \mathrm{CI})$ & OR $(95 \% \mathrm{CI})$ \\
\hline $\begin{array}{c}\text { Maternal support at } \\
\text { wave } 1\end{array}$ & $\begin{array}{c}\text { Ref } \\
\text { Upper } 50 \%\end{array}$ & $\begin{array}{c}- \\
4.75(0.60-37.46)\end{array}$ & & & \\
\hline $\begin{array}{l}\text { Maternal financial } \\
\text { support at wave } 2\end{array}$ & $\begin{array}{c}\text { Ref } \\
\text { Upper } 50 \%\end{array}$ & & & $\begin{array}{c}- \\
4.44(0.59-33.19)\end{array}$ & $\begin{array}{c}- \\
1.66(1.07-2.60)\end{array}$ \\
\hline $\begin{array}{c}\text { Child financial } \\
\text { support at wave } 2\end{array}$ & $\begin{array}{c}\text { Ref } \\
\text { Upper } 50 \%\end{array}$ & & $\begin{array}{c}- \\
0.88(0.65-1.20)\end{array}$ & & $\begin{array}{c}- \\
0.87(0.48-1.59)\end{array}$ \\
\hline
\end{tabular}

Table 2 shows results from the logistic regression models examining the association between social support and food security. As previously described in the Methods section, we limited the analyses only to the social support variables that showed significant associations with 
HAZ or BAZ (presented in Table 2). Only the level of maternal financial support in Peru was significantly positively associated with probability of having food security at wave 2 .

Table 3. Mediated effect of maternal financial support on child's HAZ in Peru via securing enough food.

\begin{tabular}{|l|c|c|c|c|}
\hline & ACME & ADE & Total effect & $\%$ of total effect mediated \\
\hline HAZ at & \multicolumn{4}{|c|}{ Upper 50\% vs. lower 50\% of maternal financial support via enough food in Peru } \\
\cline { 2 - 6 } wave 2 & $-0.01(-0.03,0.01)$ & $0.12(0.01,0.22)$ & $0.11(0.01,0.21)$ & $-0.08(-0.42,-0.04)$ \\
\hline
\end{tabular}

(ACME: average causal mediation effect, ADE: average direct effect)

Finally, causal mediation analysis using Imai et al's method was performed only in Peru, since it was the only country to show a significant association between maternal financial support

and food security (Table 3). Our model to test the mediating role of food security in linking maternal financial social support with a child's HAZ in Peru showed that the ACME of upper 50\% of maternal financial support is less than zero and statistically non-significant at $95 \%$ level, implying that role of food security is not a significant mediator of the impact of maternal financial support on child's height.

\section{Discussion}

Although there has been much effort to elucidate whether social capital has any beneficial effect on a child's nutritional status, results on the effect of maternal social capital have been mixed across studies depending on the types of social capital, child's age, and global setting. Also, improved food security has been hypothesized as one of the key mechanisms to explain the positive effect of social capital on child anthropometry, but it has never been examined empirically to our knowledge. 
Our results did not support that maternal and child support are strongly or consistently associated with a child's nutritional status. In De Silva's study (2007), the significance of associations between maternal social support and height or weight of children aged between 6 and 18 months varied across four LMICs. Significant associations with a child's height were found between the level of maternal social support in Peru, Vietnam, and Ethiopia. As for child's weight, a significant association was found only in Vietnam. However, unlike our results, the direction was consistently positive, which is assumed to be due to the difference in the age of the study population. Our analyses targeted children aged 8 years old (wave 1) and 12 years old (wave 2) which is much older compared to the sample in De Silva's analysis (2007). Height and weight at a younger age are more sensitive to feeding status or growth stimulation than in the later stage of growth. Evidence shows that catch-up growth of preterm infants measured by weight or length mainly occurred from the $10^{\text {th }}$ to $12^{\text {th }}$ month of their lives. ${ }^{36}$ Another study reported that the catchup growth of malnutrition of institutionalized children who were adopted before the age of 12 months was much larger than the children adopted after 12 months. ${ }^{37}$ Any effect of maternal social support on child's height or BMI are therefore likely to be more pronounced among younger children.

There are several suggested mechanisms explaining the positive effect of social support on the child's nutritional status. Social support enables mothers to access knowledge (e.g., how to feed their child for better nutritional status), and to give better care (e.g., practicing hygiene habits or breastfeeding for longer) ${ }^{38}$ This effect would be more marked in societies where mothers have a lower background level of education, and therefore, could not have obtained the necessary 
knowledge through schooling. Emotional support is beneficial for maternal mental health, which also can be linked to improved child growth. ${ }^{39} 40$ Martin et al (2004) provided another theory that social capital is associated with reduced odds of household hunger and food insecurity. ${ }^{16}$ Availability and access to food can be enhanced by collectively sharing information and resources. In a developing country context, sharing seeds and livestock breeds can be one of the examples. Further, in communities with strong ties, solidarity, and networks, people can share the food itself during times of hunger. ${ }^{19}$ However, our analyses revealed that the child's nutritional status was associated only with financial support both for mother and child, and food security was not a mediator.

There are several possible explanations for the lack of mediation by food insecurity. First, the YL study over-sampled poor sites, and the data from India were collected only in the state of Andhra Pradesh which is one of the poorest states. Therefore, food would not have been sufficient across the community. Even if someone had social supports these sources of supports might have not had enough food to share. In Cattel's (2001) qualitative study, individuals who are part of homogenous networks made up of poor people are less likely to receive effective support because other members are also not able to provide the required assistance. ${ }^{15}{ }^{41}$ Second, since the improvement of child anthropometry requires a continuous supply of a well-balanced diet, oneoff or sporadic type of support would not be linked to improving child anthropometry. Cultural specificity in a social network may determine to what extent and how people are able to give and take support from each other. Therefore, having someone to rely on in specific conditions may or may not mean long-term and stable support depending on the context. ${ }^{15}$ Questions about the 
strength of ties with the source of supports or frequency of receiving help from them would help uncover the practical contribution of social support to a child's nutritional status.

There are several limitations to consider when interpreting the results. First, although the YL study is a cohort survey, we could not exploit the longitudinal design for the analyses because social capital was not uniformly measured across the waves. Cross-sectional analysis limits our ability to draw causal inferences. Second, the level of maternal and child social support was arbitrarily categorized. We classified the level of maternal and child social support as being in the upper or lower $50 \%$ using median cutoff values, which was our decision to maintain a consistent standard across countries because the distribution of social support differed substantially by country. However, to reduce the possibility of bias from arbitrary operationalization of the variables, we presented results from both models wherein social support was operationalized as both a continuous and a binary variable. Finally, the data for the study is more than 15 years old, which may raise the question of whether the results remain valid under the current context. However, the findings of our study still may offer implications to other LMIC currently undergoing similar contexts of the study countries in the survey years.

Despite the several limitations, the present study contributes to our understanding of whether boosting maternal or child social support can be a practical means to improving a child's height and BMI in a resource-poor setting. Our findings suggest that interventions to strengthen social support in anticipation of a positive effect on improving child's nutritional status may be unreliable in very poor communities. Also, considering the between-country variability implies that a "one fits all" approach for enhancing social support may not be appropriate. Future research 
needs to repeat the current analysis using more sophisticated measurements of social support (i.e., measuring strength and frequency of support) and based on a more recent dataset with a larger sample size to confirm the findings.

\section{Ethical Approval and consent to participate.}

Young Lives Study provides anonymous, secondary data that is publicly available for scientific use. We downloaded the data without identifiers; thus, the confidentiality of the information given by the participants was guaranteed. Therefore, ethical approval was not required. Participants provided signed informed consent before the study commenced and were assured of confidentiality.

\section{Consent for publication}

Not applicable

\section{Availability of data and materials}

Data are available from the UK Data Service website (at https://discover.ukdataservice.ac.uk/series/?sn=2000060). Users are required to register and apply for a password with the UK Data Service and sign a confidentiality agreement before getting access to the data. Also, users are asked to inform the UK Data Service and Young Lives of analysis or publication resulting from their work with the dataset.

\section{Competing interests}

The authors declare no conflict.

\section{Funding}

There was no funding to support this study.

\section{Authors' contribution}


HYL conceived the idea. HYL, IHS, and IK designed the study. HYL analyzed the data and wrote the first draft. All authors interpreted the results. IHS and IK revised the manuscript critically. IK supervised the whole process. All authors read and approved the final manuscript.

\section{Acknowledgements}

Not applicable 


\section{References}

1. Blossner M, De Onis M, Pru“ss-U“stu“n A. Malnutrition: quantifying the health impact at national and local levels: World Health Organization 2005.

2. Miller AC, Murray MB, Thomson DR, et al. How consistent are associations between stunting and child development? Evidence from a meta-analysis of associations between stunting and multidimensional child development in fifteen low-and middle-income countries. J Public Health Nutritio 2016;19(8):1339-47.

3. Sudfeld CR, McCoy DC, Danaei G, et al. Linear growth and child development in low-and middle-income countries: a meta-analysis. J Pediatrics 2015;135(5):e1266-e75.

4. Black RE, Victora CG, Walker SP, et al. Maternal and child undernutrition and overweight in low-income and middle-income countries. The lancet 2013;382(9890):427-51.

5. UNICEF/WHO/WB. UNICEF/WHO/World Bank joint child malnutrition estimates: global and regional Accessed through : https://data.unicef.org/topic/nutrition/malnutrition/. 2020

6. UNICEF. mproving child nutrition: the achievable imperative for global progress (Accessed March 24, 2020. https://www.unicef.org/nutrition/index 68661.html). : United Nations Children's Fund, 2020.

7. Debbie L Humphries, Kirk A Dearden, Benjamin T Crookston,, Lia C Fernald, Aryeh D Stein, Tassew Woldehanna, Mary E Penny, and Jere R Behrman, on behalf of The Young Lives Determinants and Consequences of Child Growth Project Team. Cross-sectional and longitudinal associations between household food security and child anthropometry at ages 5 and 8 years in Ethiopia, India, Peru, and Vietnam. J The Journal of nutrition 2015;145(8):1924-33.

8. Dubos R. Social capital: Theory and research: Routledge 2017.

9. Lin N. Building a network theory of social capital. Connections 1999;22(1):28-51.

10. Forsman AK, Nyqvist F, Schierenbeck I, et al. Structural and cognitive social capital and depression among older adults in two Nordic regions. Aging $\mathcal{E}$ mental health 2012;16(6):771-79.

11. Watson GW, Papamarcos SD. Social capital and organizational commitment. Journal of business psychology 2002;16(4):537-52.

12. Vikram K. Social capital and child nutrition in India: The moderating role of development. Health E place 2018;50:42-51.

13. Sujarwoto S, Tampubolon G. Mother's social capital and child health in Indonesia. Social Science \& Medicine 2013;91:1-9.

14. Harpham T, De Silva MJ, Tuan T. Maternal social capital and child health in Vietnam. Journal of Epidemiology Community Health 2006;60(10):865-71.

15. De Silva MJ, Harpham T. Maternal social capital and child nutritional status in four developing countries. Health \& place 2007;13(2):341-55.

16. Martin KS, Rogers BL, Cook JT, et al. Social capital is associated with decreased risk of hunger. Social science $\mathcal{E}$ medicine 2004;58(12):2645-54. 
17. Walker JL, Holben DH, Kropf ML, et al. Household food insecurity is inversely associated with social capital and health in females from special supplemental nutrition program for women, infants, and children households in Appalachian Ohio. Journal of the American Dietetic Association 2007;107(11):1989-93.

18. Dean WR, Sharkey JR, Johnson CM. Food insecurity is associated with social capital, perceived personal disparity, and partnership status among older and senior adults in a largely rural area of central Texas. Journal of nutrition in gerontology geriatrics 2011;30(2):169-86.

19. Sseguya H, Mazur RE, Flora CB. Social capital dimensions in household food security interventions: implications for rural Uganda. Agriculture Human values 2018;35(1):117-29.

20. Barnett I, Ariana P, Petrou S, et al. Cohort profile: the Young Lives study. J International journal of epidemiology 2013;42(3):701-08.

21. group. Ys. Young lives methods guide: sampling (Available: http://www.younglives.org.uk/files/methods-guide/methods-guide-sampling).

22. Bailey K, Ferro-Luzzi A. Use of body mass index of adults in assessing individual and community nutritional status. Bulletin of the World Health Organization 1995;73(5):673.

23. Onis Md, Onyango AW, Borghi E, et al. Development of a WHO growth reference for schoolaged children and adolescents. Bulletin of the World health Organization 2007;85:660-67.

24. WHO. WHO child growth standards: training course on child growth assessment. 2008

25. UN. How to weigh and measure children: assessing the nutritional status of young children in household surveys. New York.: UN. , 1986.

26. WHO. WHO reference 2007 STATA macro package.

27. De Silva MJ, Harpham T, Tuan T, et al. Psychometric and cognitive validation of a social capital measurement tool in Peru and Vietnam. 2006;62(4):941-53.

28. Tuan T, Harpham T, Huong N, et al. Measuring social capital and mental health in Vietnam: a validity study. 2005

29. Gausman J, Austin SB, Subramanian S, et al. Adversity, social capital, and mental distress among mothers of small children: a cross-sectional study in three low and middleincome countries. 2020;15(1):e0228435.

30. Baron RM, Kenny DA. The moderator-mediator variable distinction in social psychological research: Conceptual, strategic, and statistical considerations. Journal of personality social psychology 1986;51(6):1173.

31. Imai K, Keele L, Tingley D. A general approach to causal mediation analysis. Psychological methods 2010;15(4):309.

32. Imai K, Keele L, Yamamoto T. Identification, inference and sensitivity analysis for causal mediation effects. Statistical science 2010:51-71.

33. Hicks R, Tingley D. Causal mediation analysis. The Stata Journal 2011;11(4):605-19.

34. MacKinnon DP, Lockwood CM, Williams J. Confidence limits for the indirect effect: Distribution of the product and resampling methods. Multivariate behavioral research 2004;39(1):99-128.

35. MacKinnon DP, Fairchild AJ, Fritz MS. Mediation analysis. Annu Rev Psychol 2007;58:593-614. 
36. Gong Y-H, Ji C-Y, Shan J-P. A longitudinal study on the catch-up growth of preterm and term infants of low, appropriate, and high birth weight. Asia Pacific Journal of Public Health 2015;27(2):NP1421-NP31.

37. Van IJzendoorn MH, Bakermans-Kranenburg MJ, Juffer F. Plasticity of growth in height, weight, and head circumference: meta-analytic evidence of massive catch-up after international adoption. Journal of Developmental Behavioral Pediatrics 2007;28(4):334-43.

38. Anderson AK, Damio G, Himmelgreen DA, et al. Social capital, acculturation, and breastfeeding initiation among Puerto Rican women in the United States. Journal of Human Lactation 2004;20(1):39-45.

39. Patel V, Rahman A, Jacob K, et al. Effect of maternal mental health on infant growth in low income countries: new evidence from South Asia. BMJ 2004;328(7443):820-23.

40. Harpham T, Huttly S, De Silva MJ, et al. Maternal mental health and child nutritional status in four developing countries. Journal of Epidemiology Community Health 2005;59(12):106064.

41. Cattell V. Poor people, poor places, and poor health: the mediating role of social networks and social capital. Social science \& medicine 2001;52(10):1501-16. 


\section{Supplementary Files}

This is a list of supplementary files associated with this preprint. Click to download.

- Supplementalscirep.docx 